\section{EFFECTS OF A SIGH ON THE RESPIRATORY MECHANICAL PROPERTIES IN ALI PATIENTS}

Vittorio Antonaglia, MD, ${ }^{1}$ Sara Pascotto, MD, ${ }^{1}$ Loredana De Simoni, MD, ${ }^{1}$ and Walter A. Zin, MD, $P h D^{2}$
${ }^{1}$ From the Istituto di Anestesia, Rianimazione e Terapia Antalgica, Laboratorio di Biomeccanica Respiratoria, Università degli Studi di Trieste, Trieste, Italy, ${ }^{2}$ Carlos Chagas Filho Institute of Biophysics, Federal University of Rio de Janeiro, Rio de Janeiro, Brazil.

Received 18 July 2005 Accepted for publication 14 April 2006.

Address correspondence to Dr. Vittorio Antonaglia, Ospedale di Cattinara, Dipartimento di Anestesia e Rianimazione, Laboratorio de Biomecanica Respiratoria, Strada di Fiume 447, I-34139 Trieste, Italy.

E-mail: v.antonaglia@libero.it
Antonaglia V, Pascotto S, De Simoni, Zin WA. Effects of a sigh on the respiratory mechanical properties in ALI patients

J Clin Monit Comput 2006; 20: 243-249

ABSTRACT. Objectives. The application of sighs during baseline ventilation was found to improve alveolar recruitment and oxygenation in patients with acute respiratory distress syndrome (ARDS). The present investigation evaluates if respiratory mechanics can be modified by a sigh. Methods. Ten consecutive patients with acute lung injury (ALI) admitted to the University Hospital Intensive Care Unit the were studied during mechanical ventilation. Three sighs were administered to sedated-paralyzed patients during the measurement period. Respiratory mechanics were studied in regular breaths immediately before and after a sigh provided that a steady-state had been reached and by the airway pressure-time curve profile to evaluate the lung recruitment. Viscoelastic constants (elastic, resistive, and time), as well as elastance and resistances, were determined by the single breath method. Arterial blood gases were also determined pre- and post-sigh. Results: Elastic and resistive components of viscoelasticity decreased after a sigh (20 and $21 \%$, respectively). As a result, the pressure required to overcome viscoelasticity and mechanical inhomogeneities also decreased in these patients (17\%). The mechanical changes were associated with alterations in $\mathrm{PaO}_{2}$. Conclusions: The sigh is useful to diminish viscoelastic impedance in ALI patients, thus allowing a smaller inflation pressure. Under the present experimental conditions it seems that viscoelastic mechanical alterations precede their elastic and resistive counterparts.

KEY WORDS. critical care, sigh, respiratory mechanics, resistance, elastance.

Recently the role of the sigh during mechanical ventilation in ARDS patients has been emphasized and the automatic delivery of sighs or sustained inflations by a ventilator can be considered a possible component of the ventilatory strategy in these patients [1-6].

The application of three sighs per minute during one hour of ventilation was found to improve alveolar recruitment and oxygenation in patients with ARDS in whom PEEP was adjusted using $\mathrm{PaO}_{2} / \mathrm{FiO}_{2}$ values [1, 2]. Pelosi et al. [1] also found a significant decrease in static lung elastance and respiratory resistance during the sigh period. Furthermore, it has also been demonstrated that in ARDS most of the resistance is provided by pulmonary tissue viscoelasticity [7]. Thus, in line with the results of the study of Pelosi et al. [1] it is possible to argue a modification of the viscoelastic properties of the lung during the sigh period. However, no determination of the viscoelastic constants of the respiratory system in ARDS and acute lung injury (ALI) patients has been performed in post-sigh breaths. Thus, the aims of the present investigation were to assess (1) whether sighs would modify the viscoelastic properties in 
Table 1. Characteristics and diagnosis of patients with acute lung injury (ALI)

\begin{tabular}{|c|c|c|c|c|c|c|}
\hline & Sex & $\begin{array}{l}\text { Height } \\
(\mathrm{cm})\end{array}$ & $\begin{array}{l}\text { Weigh } \\
(\mathrm{kg})\end{array}$ & $\begin{array}{l}\text { Age } \\
\text { (yrs) }\end{array}$ & Diagnosis & $\begin{array}{l}\mathrm{PaO}_{2} / \mathrm{FiO}_{2} \\
(\mathrm{mmHg})\end{array}$ \\
\hline 1 & M & 181 & 100 & 45 & $\begin{array}{l}\text { multiple } \\
\text { injury }\end{array}$ & 198 \\
\hline 2 & $\mathrm{~F}$ & 155 & 68 & 60 & pneumonia & 185 \\
\hline 3 & M & 184 & 89 & 39 & $\begin{array}{l}\text { multiple } \\
\text { injury }\end{array}$ & 215 \\
\hline 4 & $\mathrm{~F}$ & 165 & 69 & 61 & sepsis & 212 \\
\hline 5 & M & 191 & 61 & 32 & $\begin{array}{l}\text { multiple } \\
\text { injury }\end{array}$ & 197 \\
\hline 6 & M & 170 & 75 & 44 & $\begin{array}{l}\text { pneumonia } \\
\text { sepsis }\end{array}$ & 202 \\
\hline 7 & $\mathrm{~F}$ & 166 & 67 & 52 & $\begin{array}{l}\text { pneumonia } \\
\text { sepsis }\end{array}$ & 204 \\
\hline 8 & M & 184 & 89 & 67 & pancreatitis & 191 \\
\hline 9 & $\mathrm{~F}$ & 159 & 62 & 70 & sepsis & 200 \\
\hline 10 & M & 166 & 93 & 49 & burns & 227 \\
\hline Mean & & 172 & 77.3 & 51.9 & - & 200 \\
\hline SD & & 4 & 4.5 & 3.9 & - & 4 \\
\hline
\end{tabular}

ALI patients with PEEP adjusted using $\mathrm{PaO}_{2} / \mathrm{FiO}_{2}$ values; (2) whether there were differences in the mechanical properties of the respiratory system after sighs in ALI patients in whom the steady-state portion of the dynamic volumepressure (V-P) curve showed an upward concavity.

\section{MATERIAL AND METHODS}

Ten patients with ALI $\left(\mathrm{PaO}_{2} / \mathrm{FiO}_{2}<300\right.$, and bilateral infiltrates on the chest radiograph) [8], who were consecutively admitted to the intensive care unit of Cattinara Hospital, were studied. The study was always performed after hemodynamic stabilization for 1 day. The patients were sedated (propofol, $4.5 \mathrm{mg} \cdot \mathrm{kg}^{-1} \cdot \mathrm{h}$ ) and paralyzed (vecuronium $0.15 \mathrm{mg} \cdot \mathrm{kg}^{-1} \cdot \mathrm{h}$ ). Their anthropometric characteristics are provided in Table 1. None had a history or clinical evidence of either restrictive or chronic lung disease, nor cardiogenic pulmonary edema or active cardiac disease. Patients were ventilated according to the guidelines of the Consensus Conference of the American College of Chest Physicians [9], i.e., $\mathrm{FiO}_{2}$ below 0.6, adequate PEEP to support oxygenation, and low $\mathrm{V}_{\mathrm{T}}$ to avoid a plateau pressure higher than $35 \mathrm{cmH}_{2} \mathrm{O}$.

We performed a PEEP trial in each patient by applying 5, 10 and $15 \mathrm{cmH}_{2} \mathrm{O}$ PEEP during baseline ventilation, which consisted of a $\mathrm{V}_{\mathrm{T}}$ of $5.2 \pm 0.6 \mathrm{ml} \cdot \mathrm{kg}^{-1}$, constant inspiratory flow $\left(V^{\prime}\right)$ of $0.5 \pm 0.03 \mathrm{~L} \cdot \mathrm{s}^{-1}$, constant $\mathrm{FiO}_{2}$ of 0.5 , and respiratory rate amounting to 16 bpm. At $\mathrm{PEEP}=15 \mathrm{cmH}_{2} \mathrm{O}$, in any patients the plateau pressure exceeded $35 \mathrm{cmH}_{2} \mathrm{O}$. Thus, $V_{T}$ was decreased until it equalled $35 \mathrm{cmH}_{2} \mathrm{O}$. After $20 \mathrm{~min}$ at each ventilatory set we measured $\mathrm{PaO}_{2}$, and finally chose the level of PEEP at which the larger $\mathrm{PaO}_{2}$ improvement was observed, accepting possible hypercapnia as a side effect [9, 10]. Table 2 depicts the baseline ventilatory setting in ALI patients.

\section{Experimental procedure}

Patients lay in the supine position, were intubated with a cuffed Rusch tracheal tube (ID: $7.0-8.0 \mathrm{~mm}$ ), and ventilated with constant flow inflation by means of a 900C Servo Ventilator (Siemens-Elema AB, Solna, Sweden). Rapid airway occlusions were performed using a solenoid valve (Airmatic SV, Airmatic-Allied, Wilmington, OH, USA) placed next to the oral end of the tracheal tube (TT). The solenoid valve has a closing time of $11 \mathrm{~ms}$, which was measured at the Electronics Laboratory, Department of Energetics, Faculty of Engineering, Trieste, Italy, with an accelerometer (Brüel \& Kjær 4332, Brüel \& Kjær Italiana, Milan, Italy) and a current probe (AC-DC Fluke Y8100, Fluke Corporation; Everett, WA, USA). Flow $\left(V^{\prime}\right)$ was measured (linear range: $\pm 3 \mathrm{~L} \cdot \mathrm{s}^{-1}$ ) with a heated Jäger pneumotachograph (Würzburg, Germany), inserted between the TT and the solenoid valve, which was connected to a Validyne differential pressure transducer (MP-45, \pm 2 $\mathrm{cmH}_{2} \mathrm{O}$, Northridge, CA, USA) and to a carrier amplifier (13-4615-35, Gould Inc., Cleveland, OH, USA). Tracheal pressure (Ptr) was measured with a piezoresistive differential 
Table 2. Pre and post-sigh ventilatory setting and respiratory mechanics

\begin{tabular}{lcc}
\hline & Pre-sigh & Post-sigh \\
\hline Flow $\left(\mathrm{L} \cdot \mathrm{s}^{-1}\right)$ & $0.51 \pm 0.01$ & $0.51 \pm 0.01$ \\
$T \mathrm{I}(\mathrm{s})$ & $0.79 \pm 0.03$ & $0.79 \pm 0.03$ \\
$V_{\mathrm{T}}(\mathrm{L})$ & $0.40 \pm 0.02$ & $0.42 \pm 0.02$ \\
$\mathrm{RR}\left(\mathrm{breaths} \mathrm{min}^{-1}\right)$ & $16.1 \pm 0.33$ & $16 \pm 0.37$ \\
$V^{\prime} \mathrm{e}\left(\mathrm{L} \cdot \mathrm{min}^{-1}\right)$ & $6.47 \pm 0.34$ & $6.76 \pm 0.34$ \\
$\mathrm{PEEPi}\left(\mathrm{cmH}_{2} \mathrm{O}\right)$ & $1.9 \pm 1,2$ & $1.7 \pm 0.9$ \\
$\mathrm{PEEPe}\left(\mathrm{cmH}_{2} \mathrm{O}\right)$ & $7.5 \pm 0.83$ & $7.5 \pm 0.83$ \\
$\mathrm{Pst}, \mathrm{rs}\left(\mathrm{cmH}_{2} \mathrm{O}\right)$ & $16.5 \pm 0.9$ & $16.4 \pm 0.9$ \\
$\mathrm{Est}, \mathrm{rs}\left(\mathrm{cmH}_{2} \mathrm{O} \cdot \mathrm{L}^{-1}\right)$ & $22.8 \pm 1.1$ & $21.5 \pm 1.3$ \\
$\mathrm{Rint}, \mathrm{rs}\left(\mathrm{cmH}_{2} \mathrm{O} \cdot \mathrm{L}^{-1} \pm \mathrm{s}\right)$ & $3.03 \pm 0.24$ & $3.01 \pm 0.19$ \\
$\Delta P\left(\mathrm{cmH}_{2} \mathrm{O}\right)$ & $2.76 \pm 0.16$ & $2.28 \pm 0.16^{*}$ \\
$\tau_{2}(s)$ & $1.05 \pm 0.08$ & $1.05 \pm 0.06$ \\
$R_{2}\left(\mathrm{cmH}_{2} \mathrm{O} \cdot \mathrm{L}^{-1} \cdot \mathrm{s}\right)$ & $10.64 \pm 1.27$ & $8.41 \pm 0.78^{*}$ \\
$E_{2}\left(\mathrm{cmH}_{2} \mathrm{O} \cdot \mathrm{L}^{-1}\right)$ & $9.99 \pm 0.58$ & $8.03 \pm 0.60^{*}$ \\
$\mathrm{PaO}\left(\mathrm{mmHg}_{2}\right)$ & $96.9 \pm 3.5$ & $97.4 \pm 2.9$ \\
$\mathrm{PaCO}\left(\mathrm{mmHg}_{2}\right)$ & $44.5 \pm 2.1$ & $42.7 \pm 1.4$ \\
$\mathrm{Pam}\left(\mathrm{mmHg}^{-1}\right)$ & $81 \pm 6$ & $77 \pm 10$ \\
\hline
\end{tabular}

Values are means $\pm \mathrm{SD}$ of ten patients in each instances ( 3 determinations/subject). ALI, acute lung injury; TI, inspiratory time; $V_{T}$ tidal volume; $R R$, respiratory rate; $V^{\prime}$ e, minute ventilation; PEEPi, intrinsic positive end-expiratory pressure; PEEPe, external positive end-expiratory pressure Pst, elastic recoil pressure; Est, static elastance; Rint, Newtonian resistance; $\Delta P, P 1$ Pst,rs pressure dissipated against viscoelastic and inhomogeneous components; $\tau_{2}, R_{2}$, and $E_{2}$ viscoelastic time constant, resistance, and elastance, respectively; Pam, mean arterial pressure. *Significantly different from pre-sigh value $(p<0.05)$.

pressure transducer (Microswitch 142PC05D, Honeywell Ltd., Scarborough, Ontario, Canada) via a poliethylene catheter protruding $2-3 \mathrm{~cm}$ beyond the tracheal tip of the TT. The tracheal catheter (ID: $1.5 \mathrm{~mm}$ ) had six side holes and an occluded tip at its distal end. The system used to measure Ptr had a frequency response flat up to $20 \mathrm{~Hz}$. The overall dead space of the measuring equipment (excluding the TT) was $35 \mathrm{ml}$. The resistance of the equipment was $8 \mathrm{cmH}_{2} \mathrm{O} \cdot \mathrm{L}^{-1} \cdot \mathrm{s}$ at a flow of $1 \mathrm{~L} \cdot \mathrm{s}^{-1}$. $V^{\prime}$ and Ptr signals were fed through a 12-bit analogue-to-digital converter (DT2801A, Data Translation Inc., Marlboro, MD, USA) into a personal computer. Sampling frequency was $200 \mathrm{~Hz}$. Volume (V) was obtained by numerical integration of the flow signal. All data were analyzed using ANADAT data analysis software (RHT-InfoData Inc., Montreal, Quebec, Canada).

Care was taken to avoid leaks around the tracheal cuff and in the equipment. During the sampling period the cuff pressure was $40 \mathrm{cmH}_{2} \mathrm{O}$. Additionally, during the endinspiratory occlusions the pressure reached an apparent plateau, further confirming the airtightness of the experimental assembly. In all patients, ECG and arterial blood pressure were continuously monitored as well as peripheral $\mathrm{O}_{2}$ saturation and end-tidal $\mathrm{PCO}_{2}$ (Ohmeda 5250 RGM, Louisville, CO, USA). An anesthetist not involved in the experiment was continuously present to provide patient care.

The investigation was approved by the institutional review board of the Università degli Studi di Trieste, and informed consent was obtained from each patient or their next of kin.

\section{Standard respiratory mechanics and viscoelastic parameters}

The subjects were ventilated according to the aforementioned ventilatory settings. Under PEEP and before the sighs a series of consecutive breaths was collected, and $V^{\prime}$ and Ptr signals were averaged to determine the dynamic inflation V-P curve, as reported by Ranieri et al. [11]. Equation 1 was fitted to the experimental data points obtained during constant flow inflation (steady-state portion of the dynamic V-P curve):

$V=a+b \cdot \operatorname{Ptr}+c \cdot \operatorname{Ptr}^{2}$

where coefficients $a, b$, and $c$ are constants.

We performed baseline end-inspiratory occlusions to study respiratory mechanics before and after sighs by means of the single breath method (SBM) [12]. The sampling time-line was: (i) an end-expiratory occlusion for assessment of PEEPi; (ii) five breaths at baseline ventilatory settings; (iii) a 4-s end-inspiratory occlusion; (iv) five to six baseline breaths; (v) sigh; (vi) another series of 5-6 baseline breaths; (vii) an occlusion at baseline $V_{\mathrm{T}}$; (viii) 5-6 baseline breaths; (ix) end-expiratory pause (measurement of PEEPi). In each patient this sequence was repeated three times. The volume loss due to the continuous gas exchange had a negligible impact on Ptr. Heart artefacts were corrected according to Beydon et al. [13].

Immediately after the end-inspiratory occlusions (steps iii and vii above) Ptr plummeted from its peak value (Ptr, $\max )$ to an inflection point (P1). The delay between the beginning and the end of valve closure was allowed for by backextrapolation of the pressure records to the actual time of occlusion and the corrections in pressure, although very minute, were performed as previously described [14]. Thereafter a gradual decrease in Ptr led to an apparent plateau reflecting the elastic recoil pressure of the respiratory system (Pst). The difference between $\mathrm{P} 1$ and Pst $(\Delta P)$ represents the pressure dissipated against viscoelastic mechanical components and a minute degree of mechanical inhomogeneities [7, 12]. Additionally the following mechanical variables were computed: (a) Newtonian resistance $\left[\mathrm{Rint}=(\mathrm{Ptr}, \max -\mathrm{P} 1) / V^{\prime}\right]$, and $(b)$ 
static elastance of the respiratory system (Est), calculated as the difference between end-inspiratory and end-expiratory airway plateau pressures divided by $V_{T}$. Using the same occlusions the resistive component and the time constant of viscoelasticity/inhomogeneity $\left(R_{2}\right.$ and $\tau_{2}$, respectively) were determined, and $E_{2}$ (viscoelastic elastance) was computed as $R_{2} / \tau_{2}$ [12]. Arterial blood gases were analyzed immediately before and after data collection and $10 \mathrm{~min}$ after.

\section{Sigh}

During steady state conditions a series of three sighs was carried out in each individual. Five to six breaths under baseline condition were given between two consecutive sighs. While the baseline flow was kept constant $V_{T}$ was increased to values ranging from 0.88 to $1.35 \mathrm{~L}$. This was obtained by appropriately changing the frequency setting on the ventilator. After the inspiratory limb of the sigh a 5-s end-inspiratory occlusion was triggered. To choose the respiratory frequency, we combined two criteria: the inspiratory time $(T 1)>2.5 \mathrm{~s}$, to optimize the potential recruitment [15] and the product T1 $\times V^{\prime}$ had to yield a $V_{T}$ resulting in a Pst smaller than 4() $\mathrm{cmH}_{2} \mathrm{O}$ in all instances [1]. All measurements were repeated three times under the same experimental conditions. Between each test $V^{\prime}, V_{T}$ and $P_{\mathrm{tr}}$ were allowed to return to baseline values.

\section{Statistical analysis}

The normality of the data was assessed with the Kolmogorov-Smirnoff test (with Liliefors' correction), and the homogeneity of the variances evaluated by means of Levene's median test. In all cases both conditions were valid. Paired $t$-test was used to compare the data gathered before and after the sighs. Regression analysis was performed using the least squares method. The significance level was established at $5 \%(\alpha=0.05)$.

\section{RESULTS}

In all subjects the slow decay in Ptr after end-inspiratory occlusion was closely fitted by a mono-exponential function of time $(p<0.001)$. The data also closely fitted the single breath method equation, the root mean square error ranged from 0.15 to $0.21 \mathrm{cmH}_{2} \mathrm{O}$.

The mean values \pm SD's of PEEPi were similar before and after sigh $\left(1.9 \pm 1.2\right.$ and $1.7 \pm 0.9 \mathrm{cmH}_{2} \mathrm{O}$, respectively).
In 7 ALI patients the dynamic V-P curves showed an upward concavity with a positive value of the nonlinear coefficient $c$ in Equation 1 (ranging between 0.002 to 0.004 ; mean value \pm SD: $0.0025 \pm 0.0005)$. In 3 patients the dynamic V-P curves exhibited a downward concavity reflected by a negative value of c (range: -0.0004 to $-0.0006)$.

Table 2 depicts the mean values ( \pm SEM) of the mechanical parameters and ventilatory data obtained before and after sighs. $\triangle P, R_{2}$, and $E_{2}$ decreased significantly after sighs $(p<0.0001, p=0.005$, and $p<0.001$, respectively).

The mean values $\pm \mathrm{SD}$ of inspiratory duration and volume of sighs were $2.73 \pm 0.29 \mathrm{~s}$ and $1.29 \pm 0.16 \mathrm{~L}$, respectively. The mean value $( \pm \mathrm{SD})$ of differences between the plateau pressures during basal ventilation and sigh was $10.9 \pm 2.1 \mathrm{cmH}_{2} \mathrm{O}$. Considering the patients with the dynamic $V-P$ curves showing an upward or downward concavity the mean values of these differences were $10.3 \pm 2.1$ $\mathrm{cmH}_{2} \mathrm{O}$ and $12.5 \pm 1.3 \mathrm{cmH}_{2} \mathrm{O}$. respectively.

Although the overall average pre- and post-sigh values of $\mathrm{PaO}_{2}$ did not differ significantly $[96.9 \pm 11.1$ (SD) $\mathrm{mmHg}$ and $97.4 \pm 8.9$ (SD) $\mathrm{mmHg}$, respectively], it is noteworthy that only the 3 patients that presented a negative non-linear coefficient had a smaller $\mathrm{PaO}_{2}$ after sigh. If the remaining 7 patients were analyzed independently, the sigh promoted a significant increase in $\mathrm{PaO}_{2}$ [from $92.1 \pm 9.5$ (SD) $\mathrm{mmHg}$ to $97.4 \pm 9.7$ (SD) mmHg; $p=0.041$ ]. After ten minutes the patients with a negative non-linear coefficient presented no differences in gas exchange in comparison to the pre-sigh data, while the remaining 7 patients maintained a significant increase in $\mathrm{PaO}_{2}$ [from $92.1 \pm 9.5$ (SD) $\mathrm{mmHg}$ to $97.1 \pm 9.1$ (SD) mmHg; $p=0.045]$.

When the differences between the pre- and post-sigh values of $R_{2}, E_{2}$, and $\Delta P\left(\Delta R_{2}, \Delta E_{2}\right.$, and $\Delta P^{\prime}$, respectively) were plotted against the difference between pre-and post-sigh $\mathrm{PaO}_{2}\left(\Delta \mathrm{PaO}_{2}\right)$, significant inverse linear relationships were found: $\Delta \mathrm{PaO}_{2}=7.6-3.6 \cdot \Delta R_{2}, r=$ $-0.73, p=0.01$, filled circles, Figure 1; $\Delta \mathrm{PaO}_{2}=23.5-$ 12.2 $\Delta E_{2}, r=-0.64, p=0.04$, open circles, Figure 1 ; and $\Delta \mathrm{PaO}_{2}=24.3-51.8 \Delta P^{\prime}, r=-0.83, p=0.003$, Figure 2 .

\section{DISCUSSION}

The present investigation showed that within the experimental period studied and following the PEEP trial, sighs did not change significantly the mean values of $\mathrm{PaO}_{2}$ and Est in our population of patients with acute lung injury (Table 2). Nevertheless, after sighs the viscoelastic resistive and elastic constants, as well as the pressure dissipated to overcome viscoelasticity and/or mechanical inhomo- 


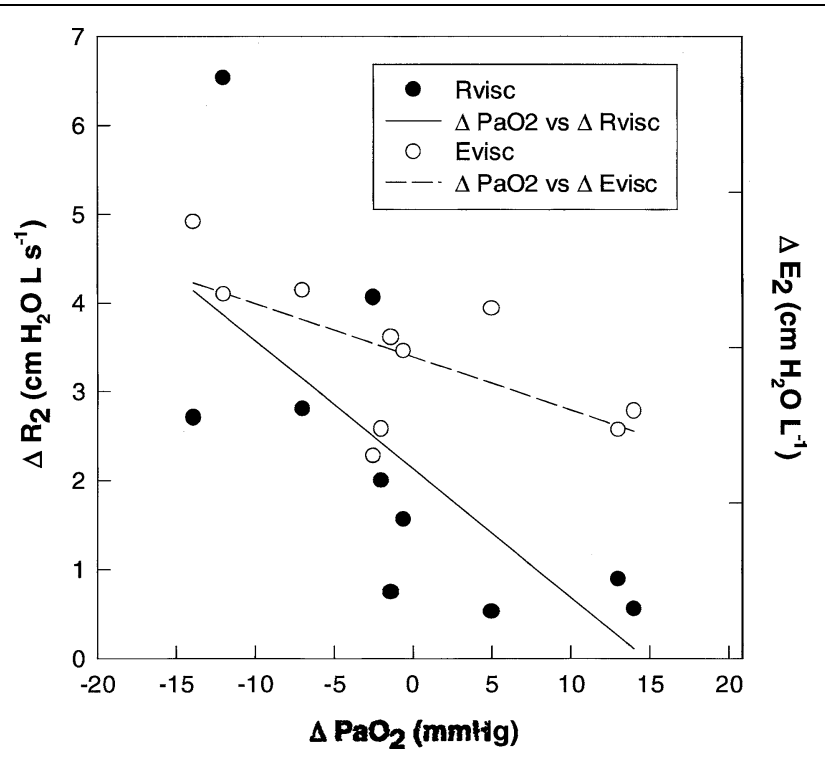

Fig. 1. Relationships between the variation between the pre- and post-sigh values of the viscoelastic resistive and elastic constants $\left(\Delta R_{2}\right.$ and $\Delta E_{2}$, respectively) and the difference in $\mathrm{PaO}_{2}$ measured under the same conditions $\left(\triangle \mathrm{PaO}_{2}\right)$ in 10 patients with acute lung injury. The solid line and circles pertain to $\triangle \mathrm{PaO} \mathrm{O}_{2}$ vs. $\Delta R_{2}\left(\triangle \mathrm{PaO} \mathrm{O}_{2}=7.6-3.6 \pm \Delta R_{2}, r=\right.$ $-0.73, p=0.01)$, whereas the broken line and open circles refer to the $\Delta \mathrm{PaO}_{2}$ vs. $\Delta E_{2}$ relationship $\left(\Delta \mathrm{PaO} \mathrm{O}_{2}=23.5-12.2 \Delta E_{2}, r=\right.$ $-0.64, p=0.04)$.

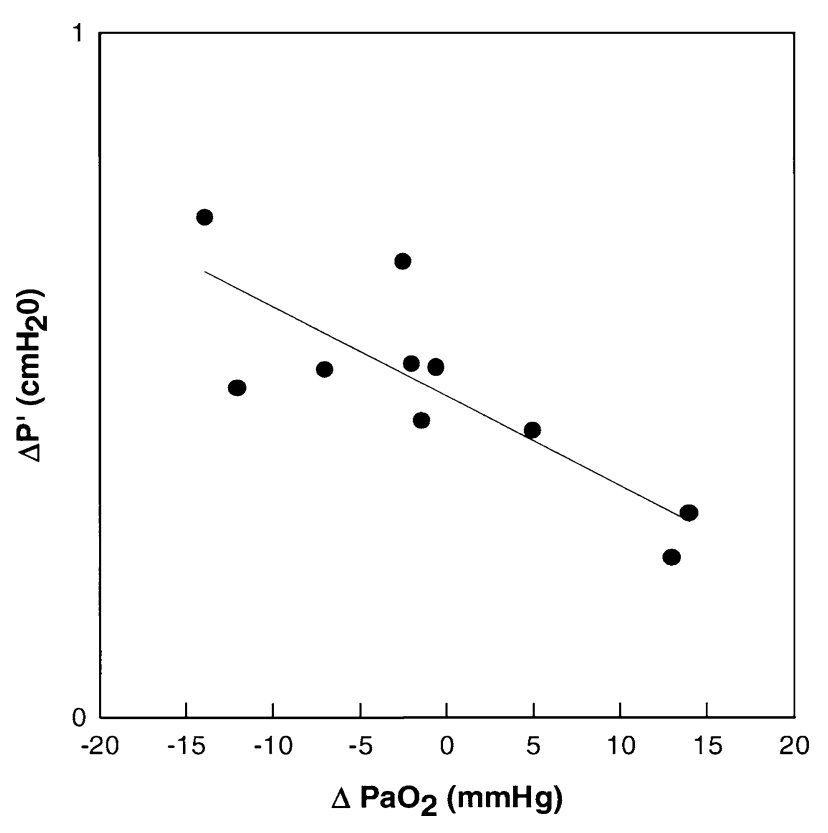

Fig. 2. Relationships between the variation between the pre- and postsigh values of the pressure $\left(\Delta P^{\prime}\right)$ dissipated against viscoelastic and inhomogeneous mechanical components $(\mathrm{P} 1-\mathrm{P} 2)$ and the difference in $\mathrm{PaO}_{2}$ measured under the same conditions $\left(\triangle \mathrm{Pa} \mathrm{O}_{2}\right)$ in 10 patients with acute lung injury. The solid line represents the regression line $\left(\Delta \mathrm{PaO} \mathrm{O}_{2}=\right.$ $24.3-51.8 \pm \Delta P, r=-0.83, p=0.003)$. geneities within the system, decreased in ALI patients. Additionally, in the patients in who the differences between these variables were larger, the increase in $\mathrm{PaO}_{2}$ was higher.

Our analysis was based on the assumption that the respiratory system behaves as a linear viscoelastic model, which clearly should not be regarded as a complete and perfect representation of respiratory mechanics. More complex nonlinear viscoelastic [16] and viscoplastoelastic models [17] have been used to explain volume- and timedependence of energy dissipation within the respiratory system. Nevertheless, the linear viscoelastic model has been shown to provide an accurate description of the timedependence of resistance and elastance over the lung volume and flow ranges used in the present study $[18,19]$.

The baseline values of the respiratory mechanical parameters reported in Table 2 are not different from those previously found in ALI patients $[12,20]$. The introduction of a sigh into a regular pattern of baseline breaths decreased $\Delta \mathrm{P}$ in ALI patients, although not back to normal values $[12,18]$, indicating that the viscoelastic properties and/or inhomogeneities of the system could be improved by the maneuver, i.e., impedance decreased. In this context, no report has been found in the literature concerning the measurement of the viscoelastic constants $\left(\tau_{2}, R_{2}\right.$, and $\left.E_{2}\right)$ after sighs. These constants, however, were determined in normal subjects [12, 16, 17], ARDS [7] and COPD patients [21] to evaluate the time-, flow-, and volume-dependence of respiratory resistance and elastance.

In the present study $\tau_{2}, R_{2}$, and $E_{2}$ were not different from those obtained in previous studies in ALI patients $[12,20]$. However, we obtained post-sigh values of $R_{2}$, and $E_{2}$ significantly smaller than the pre-sigh ones, while $\tau_{2}$ was not significantly different (Table 2 ). This probably resulted from either a resetting of the viscoelastic mechanical components of the respiratory system. i.e., returning their elastic and resistive components to baseline mechanical conditions, and/or to the recruitment of atelectatic air spaces in the diseased lungs.

In previous studies in ARDS patients [1-6] lung volume recruitment during sighs was associated with a significant increase in $\mathrm{PaO}_{2}$. Interestingly enough we found that the higher the change in $\mathrm{PaO}_{2}$ measured before and after sighs, the greater the decrease in $\Delta P$ (Figure 2). The same behavior was presented by $\Delta E_{2}$ and $\Delta R_{2}$ (Figure 1). $\Delta \mathrm{P}$ is determined by the actual values of $E_{2}$ and $R_{2}$ at any given time throughout the breathing cycle, and, hence, according to the viscoelastic model of the respiratory system, it is conceivable that the constants assume new values after a deep breath, yielding a change in $\Delta P$. On the other hand, the sigh will recruit collapsed air spaces and minimize mechanical inhomogeneities [1], thus decreasing $\triangle P, E_{2}$ and $R_{2}$. Neumann et al. [15] found that recruitment occurred mainly within the first $4 \mathrm{~s}$ of breath-holding procedures in 
different lung injury models. In our investigation the mean value of the inspiratory time was of $2.73 \pm 0.29 \mathrm{~s}$ and presumably the potential recruitment occurred mainly within this time.

Previous studies in ARDS patients demonstrated a decrease in Est after the delivery of a deep breath [1-4]. We did not find such a result (Table 2). The disagreement between the reports could be secondary to different experimental designs: (i) they used a distending pressure around $40 \mathrm{cmH}_{2} \mathrm{O}$ for about $40 \mathrm{~s}$, whereas in the present investigation an inspiratory duration of $2.7 \mathrm{~s}$ was applied instead. The longer distending pressure could have opened more air spaces to a greater extent [3]; (ii) Pelosi et al. [1] used three sighs per minute for at least one hour; (iii) Patronitti et al. [4] used sighs during pressure support ventilation; and (iv) our patients were less severe than theirs (ALI $\times$ ARDS), so that a recruitment maneuver could be more effective in ARDS.

Ranieri et al. [11] reported that in ARDS patients the dynamic volume-pressure curve represents a clinical tool to detect hyperinflation and to predict the effects of PEEP on alveolar recruitment. In accordance with them [11] we found that the patients with negative $c$ values (Equation 1) had the highest values of static elastance and endinspiratory plateau pressure, and a tendency to show a fall in $\mathrm{PaO}_{2}$ after a sigh. Moreover, we found that the patients with the dynamic V-P curves showing an upward concavity had a lower difference between the values of the plateau pressure during sigh and basal tidal volume $\left(10.3 \pm 2.1 \mathrm{cmH}_{2} \mathrm{O}\right)$ in comparison to those of the patients with dynamic $\mathrm{V}-\mathrm{P}$ curves showing an downward concavity $\left(12.5 \pm 1.3 \mathrm{cmH}_{2} \mathrm{O}\right)$. The higher sigh plateau pressure in the latter patients can be related to the overstretching pressure in the ventilated alveolar distrects. Thus, hyperinflation probably increased with sigh in the latter patients. In the other 7 patients, presenting a positive $c$ value, recruitment probably occurred [11], explaining the increase in $\mathrm{PaO}_{2}$ after the sigh. Conversely, the mean value of $\mathrm{PaCO}_{2}$ had the tendency to decrease after sigh (Table 2), but in the patients with dynamic V-P curves showing an downward concavity $\mathrm{PaCO}_{2}$ remained unchanged (before sigh $44.2 \pm 1.9$, after sigh $44.4 \pm 1.7 \mathrm{mmHg}$ ). A possible explanation is that the potential increase of $\mathrm{PaCO}_{2}$ related to hyperinflation in these patients was counterbalanced from the changes in hemodynamics due to reduction in mean arterial pressure after sigh, that in these patients was of $15 \pm 3 \mathrm{mmHg}$ (Table 2). These results were confirmed from the modifications of ges exchange ten minutes after sigh. $\mathrm{PaO}_{2}$ remained higher and $\mathrm{PaCO}_{2}$ lightly lower than the pre-sigh values in the patients with $V-P$ curves showing an upward concavity, while $\mathrm{PaO}_{2}$ and $\mathrm{PaCO}_{2}$ returned to the values pre-sigh in the patients with $\mathrm{V}-\mathrm{P}$ curves showing an downward concavity, indicating a strong de- pendency by the hemodynamic fluctuation in these latter patients.

Potential limitations of the present investigation can be considered: (a) lung recruitment was assessed by a single method; (b) the measurement of $\Delta P$ was obtained with a precise experimental method. We used the airway pressuretime curve profile [11] to evaluate the lung recruitment. Other more sophisticated methods to assess a potential alveolar recruitment can be used [1, 22-25] and further studies have to be performed to compare the results of these methods with the modifications of the viscoelastic properties after a sigh. The measurement of $P 1$ represents a critical point in the assessment of $\Delta P$. In our experimental setting P1 was obtained by backextrapolation. The results of the present study have to be confirmed by measuring $\Delta P$ in clinical practice. On the other side, the airway pressuretime curve profile was recentely confirmed as a good predictor of recruitment and/or hyperinflation [26] and our results can be considered the first analysis of the viscoelastic properties after a sigh and, taking into consideration the bedside evaluation of the changes in viscoelastic constants, the measurement of $\Delta P$ can represent an easier approach than the actual determination of $E_{2}$ and $R_{2}$. Thus, if further studies will confirm our results, it will he possible to consider the measurement of $\Delta P$ as a very helpful when evaluating the diverse sigh patterns presently available to recruit collapsed air spaces [1, 3, 6].

In conclusion, in ALI patients the pre- and postsigh determination of the viscoelastic constants and/or the pressure dissipated to overcome mechanical inhomogeneities might indicate an improvement in the mechanical impedance of the respiratory system earlier than the results yielded by the tradicional static elastance or resistance.

The authors are very grateful to Prof. Paolo Pelosi for his invaluable comments and suggestions.

\section{References}

1. Pelosi P, Cadringher P, Bottino N, Panigada M, Carrieri F, Riva E, Lissoni A, Gattinoni L. Sigh in acute repiratory distress syndrome. Am J Respir Crit Care Med 1999; 159: 872880.

2. Pelosi P, Bottino N, Chiumello D, Caironi P, Panigada M, Gamberoni C, Colombo G, Bigatello LM, Gattinoni L. Sigh in supine and prone position during acute repiratory distress syndrome. Am J Respir Crit Care Med 2003; 167: 521-526.

3. Grasso S, Mascia L, Del Turco M, Malacarne P, Giunta F, Brochard L, Slutsky A, Ranieri MV. Effects of recruitig maneuvers in patients with acute respiratory distress syndrome ventilated with protective ventilatory strategy. Anesthesiology 2002; 96: 795-802. 
4. Patroniti N, Foti G, Cortinovis B, Maggioni E, Bigatello LM, Cereda V, Pesenti A. Sigh improves gas exchange and lung volume in patients with acute respiratory distress syndrome undergoing pressure support ventilation. Anesthesiology 2002; 96: 788-794.

5. Pelosi P, Chiummello D, Calvi E, Taccone P, Bottino N, Panigada M, Cadringher P, Gattinoni L. Effects of different continuous positive airway pressure devices and periodic hyperinflations on respiratory function. Critical Care Med 2001; 29: 1683-1689.

6. Lim CM, Koh Y, Park W, Chin JY, Shim TS, Lee SD, Kim WS, Kim DS, Kim WD. Mechanistic scheme and effect of "extended sigh" as a recruitment maneuver in patients with acute respiratory distress syndrome: a preliminary study. Crit Care Med 2001; 29: $1255-1260$.

7. Eissa NT, Ranieri VM, Corbeil C, Chassé M, Robatto FM, Braidy J, Milic-Emili J. Analysis of behaviour of the respiratory system in ARDS patients: effects of flow, volume and time. J Appl Physiol 1991; 70: 2719-2729.

8. Bernard GR, Artigas A, Brigham KL, Carlet J, Falke K, Hudson L, Lamy M, Morris A, Spragg R. The American-European Consensus Conference of ARDS: definitions, mechanisms, relevant outcomes, and clinical trial coordination. Am J Respir Crit Care Med 1994; 149: 818-824.

9. Slutsky AS. Consensus conference on mechanical ventilation, Part I. Intensive Care Med 1994; 20: 64-79.

10. Amato MBP, Barbas CSV, Madeiros DM, Magaldi MB, Schettino GPP, Lorenzi-Filho G, Kairalla A, Deheinzelin D, Munoz C, Oliveira R, Takagaki TY, Carvaslho CRR. Effect of a protective-ventilation strategy on mortality in the acute respiratory distress syndrome. N Engl J Med 1998; 338: 347-354.

11. Ranieri VM, Giuliani R, Fiore T, Dambrosio M, Milic-Emili $\mathrm{J}$. Volume-pressure curve of the respiratory system predicts effects of PEEP in ARDS: "Occlusion" versus "Constant flow" Technique. Am J Respir Crit Care Med 1994; 149:19-27.

12. Antonaglia V, Grop A, Demanins P, Beltrame F, Lucangelo U, Peratoner A, De Simoni L, Gullo A, Milic-Emili J. Single-breath method for assessing the viscoelastic properties of the respiratory system. Eur Respir J 1998; 12: 1191-1196.

13. Beydon L, Svantesson C, Brauer K, Lemaire F, Jonson B. Respiratory mechanics in patients ventilated for critical lung disease. Eur Respir J 1996; 9: 262-273.

14. Bates JHT, Hunter IW, Sly PD, Okubo S, Filiatrault S, MilicEmili J. Effect of valve closure time on the determination of respiratory of respiratory resistance by flow interruption. Med Biol Eng Comput 1987; 25: 136-140.

15. Neumann P, Berglund JE, Fernandez Mondejar E, Magnusson A, Hedenstierna G. Dynamics of lung collapse and recruitment during prolonged breathingin porcine lung injury. J Appl Physiol 1998; 85: 1533-1543.

16. Suki B, Bates JHT. A non linear viscoelastic model of lung tissue mechanics. J Appl Physiol 1991; 71: 826-833.

17. Hildebrandt J. Pressure-volume data of cat lung interpreted by a plastoelastic linear viscoelastic model. J Appl Physiol 1970; 28: 365-372.

18. D'Angelo E, Calderini E, Torri G, Robatto FM, Bono D, Milic-Emili J. Respiratory mechanics in anesthetized paralyzed humans: effects of flow, volume, and time. J Appl Physiol 1989; 67: $2556-2564$.

19. D'Angelo E, Tavola M, Milic-Emili J. Volume and time dependence of respiratory system mechanics in normal anaesthetized paralysed humans. Eur Respir J 2000; 16: 665-672.

20. Antonaglia V, Peratoner A, De Simoni L, Gullo A, Milic-Emili J, Zin W. Bedside assessment of respiratory viscoelastic properties in ventilated patients. Eur Respir J 2000; 16: 302-308.

21. Guerin C, Coussa M-L, Eissa NT, Corbeil C, Chassé M, Braidy J, Matar N, Milic-Emili J. Lung and chest wall mechanics in mechanically ventilated COPD patients. J Appl Physiol 1993; 74: 1570-1580.

22. Rothen HU, Sporre B, Engberg G, Wegenius G, Hedenstierna G. Re-expansion of atelectasis durino general anestesia: A computed tomography study. Br J Anaesth 1993: 71: 788-795.

23. Tokics L, Hedenstierna G, Strandberg A, Brismar B, Lundquist $\mathrm{H}$. Lung collapse and gas exchange during general anesthesia: effects of spontaneous breathing, muscle paralysis, and PEEP. Anesthesiology 1987; 66: 157-167.

24. Gunnarsson L, Tokics L, Gustavsson H, Hedenstierna G. Influence of age on atelectasisn formation and gas exchange impairment during general anesthesia. Br J Anaesth 1991; 66: 423-432.

25. Tokics L, Hedenstierna G, Svensson L, Brismar B, Cederlund T, Lundquist $\mathrm{H}$, Strandberg A. V/Q distribution and correlation to atelectasis in anesthetized paralyzed humans. J Appl Physiol 1996; 81: 1822-1833.

26. Grasso S, Terragni P, Mascia L, Fanelli V, Quintel M, Herrmann P, Hedenstierna G, Slutsky A S, Ranieri VM. Airway pressure-time curve profile (stress index) detects tidal recruitment/hyperinflation in experimental acute lung injury. Crit Care Med 2004; 32: 1018-1027. 